\title{
Design optimization of heating plates for hydraulic presses
}

\author{
Evgeniy Malygin ${ }^{1}$, Mikhail Krasnyanskiy ${ }^{1}$, and Vladimir Mokrozub ${ }^{1, *}$ \\ ${ }^{1}$ Tambov State Technical University, 392000, Sovetskaya, 106, Tambov, Russia
}

\begin{abstract}
The paper describes the problem of design optimization of heating plates for hydraulic presses used for heat treatment of rubber, plastics, and metals. The problem involves finding the number and capacity of heaters or the heating steam pressure, the appropriate configuration of slots for heaters or steam supply channels to ensure the required heating rate of the plate to the operating temperature, and the permissible level of non-uniformity of the temperature field of its working surface. The adequacy of the mathematical description of the thermal process in heating plates for presses is confirmed by comparing the results of the solution of mathematical models with the data of the industrial experiments. The results of solving the problem for induction heating plates and resistive heating plates are presented.
\end{abstract}

\section{Introduction}

Heating plates are the main elements of heating systems for hydraulic presses used for heat treatment of rubber, plastics, metals and alloys. The selection of the plate design depends on the type of heating, the number and capacity of heaters (inductors or RTDs), configuration of slots, and in the case of steam heating - the required steam pressure and configuration of steam channels. The most widespread method of heating plates of industrial presses at operating temperatures up to $250{ }^{\circ} \mathrm{C}$ is induction, because induction heaters are easy to manufacture, economical and durable. At high operating temperatures, the use of induction heating is necessitated by the use of electric current generators with a frequency of $50 \mathrm{~Hz}$; thus, the use of resistive heaters is considered to be more efficient (RTDs). Regarding the use of saturated steam for heating of the plates, this method is not as energy efficient as the induction heating, as described in [1], and it has fewer possibilities for forming working temperature fields of desired configuration on the working surfaces of the plate. In addition, it is more complicated to implement.

The present paper addresses the issues of selecting optimum parameters for heating plates designs, and modeling of their temperature fields.

\section{Statement of the Problem}

As a rule, design and engineering departments of industrial enterprises have to solve the problem of maintaining the desired degree of non-uniformity of temperature fields of working surfaces of single uninsulated heating plates of designed presses рабочих (from \pm 5 to $\pm 1^{\circ} \mathrm{C}$ ). It is assumed that the use of such plates would ensure the uniform heating of press molds and workpieces and, as a result, it would increase the possibility of manufacturing a wide range of products. Therefore, design optimization of heating plates for presses involves determining the number and power of heaters or pressure of the heating steam, the appropriate configuration of slots to accommodate the heaters or channels to supply the heating steam. This will ensure the required rate of heating the plate up to operating temperature, and permissible level of non-uniformity of temperature field of its working surface.

It is proposed to use the difference between the maximum and minimum operating temperatures of the surface of the plate as the optimality criterion:

$$
\Delta=\max _{x, y} T\left(x, y, w, \tau_{h}\right)-\min _{x, y} T\left(x, y, w, \tau_{h}\right),
$$

where $\delta \leq x \leq(l-\delta) ; \delta \leq y \leq(s-\delta) ; l, s$ is the length and width of the plate, respectively, $\mathrm{m} ; \delta$ is the width of the plate edge, which is not included in the working surface, $\mathrm{m} ; w=h$ is the plate height, $\mathrm{m}$, if the working surface is its upper surface, and if the working surface is its lower surface, then $w=0 ; \tau_{z}$ is the predetermined duration of heating the working surface of the plate from the ambient temperature $T_{0}$ to the predetermined temperature $T_{z}$, sec.

It is necessary to find the number of heaters or steam channels $n$, the necessary capacity of each of them, the configuration of the steam channels or slots to accommodate heaters $\mathbf{G}^{(i\rangle}$, at which the function (1) reaches a minimum value and the following restrictions are fulfilled.

1. Temperature difference on the working surface of the plate:

$$
\left|T\left(x, y, w, \tau_{z}\right)-T_{z}\right| \leq \Delta T_{z} \forall(x, y) \in S_{p},
$$

where $\Delta T_{z}$ is the predetermined values of the permissible temperature difference on the working surface of the

*Corresponding author: mokr@mail.gaps.tstu.ru 
plate, ${ }^{\circ} \mathrm{C} ; S_{p}$ is a set of points positions on the working surface of the plate (as a point $(0,0)$ is taken the lower left corner of the plate).

2. geometric dimensions of slots for heaters or steam channels and their position in the plate:

$$
\mathbf{G}_{\min }^{\langle i\rangle} \leq \mathbf{G}^{\langle i\rangle}<\mathbf{G}_{\max }^{\langle i\rangle}, i=1, \ldots, n,
$$

where $\mathbf{G}^{\langle i\rangle}$ is a vector of slot parameters of the $i$-th heater or steam channel.
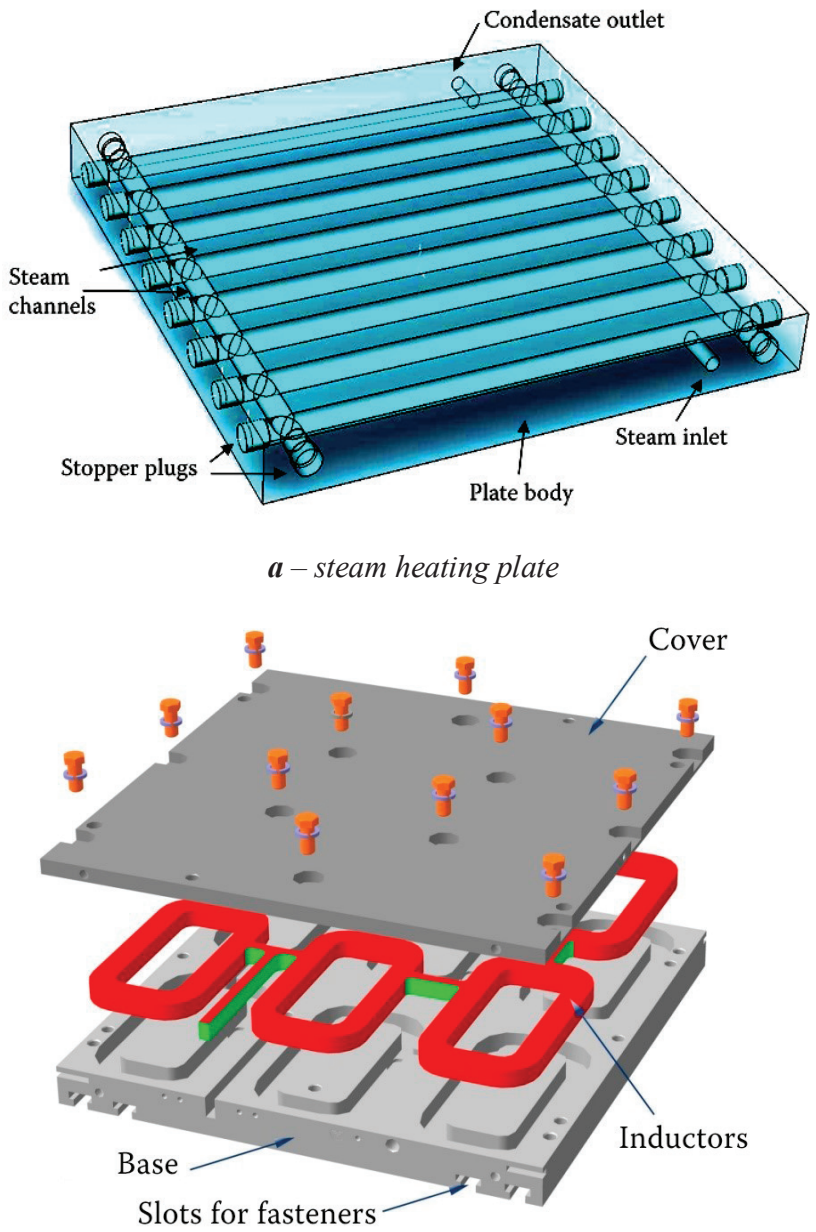

$\boldsymbol{b}$-induction heating plate

Fig.1. Designs of heating plates for presses

Configuration of steam channels of industrial heating plates generally corresponds to the one shown in Fig.1a, therefore, the components of the vectors $\mathbf{G}^{\langle i\rangle}, i=1, \ldots, n$ are the inner diameter of the channel $\left(d k_{i}\right)$ and the distance between its axis and the axes of adjacent channels (on the left $-b l_{i}$ and on the right $-b r_{i}$ ), or the adjacent channel axis and the edge of the working surface of the plate.

Induction heaters of industrial heating plates are typically wire coils in the shape of rectangles, as shown in Fig. 1b. In such a case, the components of the vector $\mathbf{G}^{\langle i\rangle}$ are the depth $\left(g_{i}\right)$, and the width $\left(b_{i}\right)$ of the slot of the $i$-th inductor, the length $\left(l_{i}\right)$ and the width $\left(s_{i}\right)$ of the inductor, $\mathrm{x}$-coordinate $\left(x c_{i}\right)$ and $\mathrm{y}$-coordinate $\left(y c_{i}\right)$ of its geometric center, the values of which have to ensure the fulfillment of restrictions on the distance between the slots of adjacent inductors, between the inductor slot and edges of the working surface of the plate.

Resistive heaters (RTDs) are a wire made of a material with high electrical resistance (nichrom, fechral), coiled into a spiral. The shape of slots can be arbitrary; therefore, the components of vector $\mathbf{G}^{\langle i\rangle}$ for the resistive heater are the depth $\left(g_{i}\right)$ and the width $\left(b_{i}\right)$ of the slot cross section, as well as the bending radius of its axis $\left(R_{i}\right)$, the value of which is limited by the restriction on the bending radius of the spiral: the adjacent turns shall be external, see. Fig. 2.

The minimum permissible bending radius of the slot axis $R_{\min }$ is determined by the condition

$$
h_{0}>2 d \text {, }
$$

where $h_{0}=h-\frac{h D}{2 R}$ is distance between turns of spiral on the inner radius, $\mathrm{m}$, as shown in Fig. $2 ; d$ is the heater wire diameter, $\mathrm{m} ; h$ is the winding pitch of the straight spiral, $\mathrm{m} ; D$ is the winding diameter of the spiral on the midline, $\mathrm{m} ; R$ is the bending radius of the spiral along the axial line, $\mathrm{m}$.

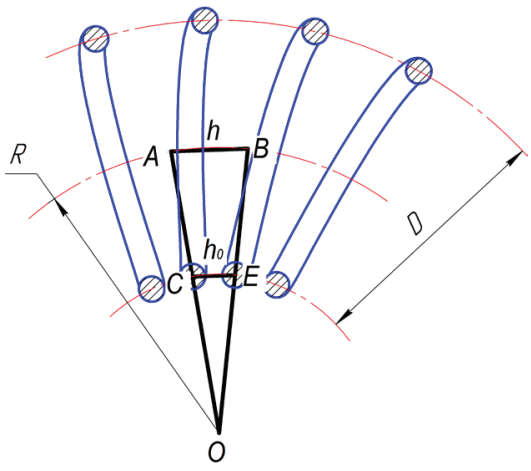

Fig. 2. Sectional vies of the bending spiral fragment

In addition, the position of slots for RTDs in the heating plate is limited by the restriction

$$
V_{i} \cap V_{j}=\varnothing, i, j=1, \ldots, n, i \neq j
$$

where $V_{i}$ is the volume of the $i$-th slot of the heater with the inclusion of the surrounding area defined by restrictions on the distance between the slots of adjacent heaters, the heater slot and the boundaries of the working surface of the plate $\left(\mathrm{m}^{3}\right)$.

3. The length of the wire of the induction or resistive heater. For the induction heater the restriction on the number of coils $\left(n v_{i}\right)$ of the wire of a given diameter given the insulation $\left(d i_{i}\right)$ is as follows:

$$
n v_{i} \leq \frac{4 \cdot b_{i} \cdot g_{i} \cdot \chi_{i}}{\pi \cdot d i_{i}^{2}}, i=1, \ldots, n
$$

where $\chi_{i}$ is the slot fill factor.

For the resistive heater:

$$
\gamma_{i} \frac{U_{i}^{2} \pi d_{i}^{2}}{4 P_{i}} \leq L_{i} \leq \frac{L p_{i}}{t_{i}} \sqrt{\left(\pi D_{i}\right)^{2}+t_{i}^{2}}, i=1, \ldots, n,(7)
$$


where $L_{i}$ is the wire length of the $i$-th heater, $\mathrm{m} ; D_{i}, t_{i}$ is the average diameter and the wire winding step of the $i$ th heater, $\mathrm{m} ; L p_{i}$ is the slot length to accommodate the $i$ го heater, $\mathrm{m}$;

$$
d_{i}=\sqrt[3]{\frac{4 Q_{i}^{2}}{\gamma_{i} U_{i}^{2} W_{i} \pi^{2}}} \text { is the required diameter of its }
$$

of wire, $\mathrm{m}$, see in [2]; $\gamma_{i}$ is specific electric conductivity of the heater material, $\mathrm{ohm}^{-1} \mathrm{~m}^{-1} ; U_{i}$ is voltage applied to it, $\mathrm{V} ; Q_{i}$ is rated power of the $i$-th heater, W; $W_{i}$ is its surface power, $\mathrm{W} / \mathrm{m}^{2}$, see in [3].

4. The total capacity, which provides a desired heating rate of the plates and the heat losses are compensated by the ambient air:

$$
\sum_{i=1}^{n} Q_{i} \geq \frac{l \cdot s \cdot h \cdot \rho}{\tau_{z}} \int_{T_{0}}^{T z} c(T) d T+\sum_{r=1}^{6} \alpha_{r} S_{p l, r}\left(T_{r}-T_{0}\right),
$$

where $c, \rho$ are specific heat capacity, $\mathrm{J} \cdot \mathrm{kg}^{-1} \cdot \mathrm{K}^{-1}$, and density, $\mathrm{kg} / \mathrm{m}^{3}$ of the plate material, respectively; $S_{p l, r}$ is the area of the $r$-th surface of the heating plate: working surface, the cover, the side ends, $\mathrm{m}^{2} ; \alpha_{r}$ is the heat transfer coefficient from the $r$-th surface of the plate, $\mathrm{W} \cdot \mathrm{m}^{-2} \mathrm{~K}^{-1}$, see in [4]; $T_{r}$ is the average temperature of the $r$-th surface of the plate, ${ }^{\circ} \mathrm{C}$, for a period of time $\left[0, \tau_{z}\right]$.

We note that power generated in the time period $\left[0, \tau_{z}\right]$ in each of the plate channels of steam heating can be found according to [4]:

$$
Q_{i}=\frac{G_{i} r\left(t_{\Pi}\right)}{\tau_{z}}, i=1, \ldots, n,
$$

where $G_{i}$ is steam flow through the $i$-th channel, $\mathrm{kg} / \mathrm{s}$; $r\left(t_{\Pi}\right)$ is specific heat of steam condensation at a temperature $t_{\mathrm{\Pi}}, \mathrm{J} / \mathrm{kg}$.

To determine the temperature field of the working surface of the plate it is necessary to solve the heat equation with internal heat sources [5]:

$$
\frac{\partial T}{\partial \tau}=a \nabla^{2} T+\frac{q}{c \rho},
$$

where $T=T(x, y, z, \tau)$ is the temperature in the poing ot the volume plate with coordinates $(x, y, z)$ at the moment of time $\tau,{ }^{\circ} \mathrm{C} ; q=q\left(x, y, z, T_{a v}\right)$ is the specific heat generation is this point, $\mathrm{W} / \mathrm{m}^{3}$;

$$
T_{a v}=T_{a v}(\tau)=\frac{1}{h \cdot s \cdot l} \cdot \int_{0}^{h} \int_{0}^{s} \int_{0}^{l} T(x, y, z, \tau) d x d y d z \text { is }
$$

the average temperature, ${ }^{\circ} \mathrm{C}$, of the plate in the moment of time $\tau ; a=\lambda /(c \rho)$ is the coefficient of temperature conductivity of the plate material, $\mathrm{m}^{2} / \mathrm{s} ; \lambda$ is its heat conductivity coefficient, $\mathrm{W} \cdot \mathrm{m}^{-1} \mathrm{~K}^{-1}$.

The initial condition for the solution of equation (9)

$$
T(x, y, z, 0)=T_{0} .
$$

Heat transfer from the external surfaces of the noninsulated heating plate is described by the boundary conditions of the third kind:

$$
-\left.\lambda \frac{\partial T}{\partial n}\right|_{S_{p l, r}}=\alpha_{r}\left(T_{r}-T_{0}\right), r=1, \ldots, 6
$$

The method for determining the intensity of internal heat release in the plate $q\left(x, y, z, T_{a v}\right)$ depends on the method of heating. For the steam heating plate, see Fig. 1a, if we assume identity and uniformity of heat release throughout the volume of each steam channel, we obtain:

$q\left(x, y, z, T_{a v}\right)=\left\{\begin{array}{l}\frac{4 \cdot \alpha_{\Pi} \cdot\left(t_{\Pi}-T_{a v}\right)}{d k_{i}}, \text { if }(x, y, z) \in v k_{i}, i=1, \ldots, n \\ 0, \text { otherise }\end{array}\right.$

where $\alpha_{п}$ is coefficient of heat transfer of condensing steam in horizontal cylindrical channels, $\mathrm{W} \cdot \mathrm{m}^{-2} \mathrm{~K}^{-1}$, see in [4]; $t_{\Pi}$ is the steam condensation temperature, ${ }^{\circ} \mathrm{C} ; v k_{i}$ is the volume of the $i$-th channel of plate, $\mathrm{m}^{3}$.

For induction heating plate, see Fig. 1b, if we assume that heat release of each inductor is uniform in the slot volume designed for it, and the characteristics of the material volume to be filled with the inductor coil and special paste correspond to the characteristics of the material plate, we obtain:

$$
q(x, y, z)=\left\{\begin{array}{l}
q_{a v 0 i}, \text { if }(x, y, z) \in v_{i}, i=1, \ldots, n \\
0, \text { otherwise }
\end{array}\right.
$$

where $q_{a v 0 i}$ is the average specific power of the $i$-th inductor for the period $\left[0, \tau_{z}\right], \mathrm{W} / \mathrm{m}^{3} ; v_{i}$ is the volume for the released power of the $i$-th inductor. $\mathrm{m}^{3}$.

Consequently

$$
q_{a v 0 i}=\frac{Q_{a v i}}{2 b_{i} \cdot g_{i}\left(s_{i}+l_{i}-2 b_{i}\right)},
$$

where $Q_{a v i}$ is the average power of the $i$-th inductor for the period $\left[0, \tau_{z}\right], W$, see in [6].

Rounded corners of inductors shown in Fig. 1b, greatly complicate the solution of the equation (9), and therefore we make an assumption about their absence, with the total length of the rectangular inductor equal to the length of the real one.

For the resistive heating plate, if we assume uniform heat release in the volume of the slot where the heater is accommodated, then

$$
q(x, y, z)=\left\{\begin{array}{l}
\frac{Q_{i}}{v_{i}}, \text { if }(x, y, z) \in v_{i}, i=1, \ldots, n, \\
0, \text { otherwise, }
\end{array}\right.
$$

To solve equation (10) under the conditions (11), (12), (13) or (14), (15) or (16) we used the system of finite element analysis ANSYS [7]. The adequacy of the proposed mathematical description of the industrial processes of induction heating plates and resistive heating plated was confirmed by comparing the calculation results with the results of experiments conducted at JSC "ARTI-Zavod", Tambov, see Fig. 3a, and JSC "Zavod Tambovpolimermash", see Fig. 3b. 


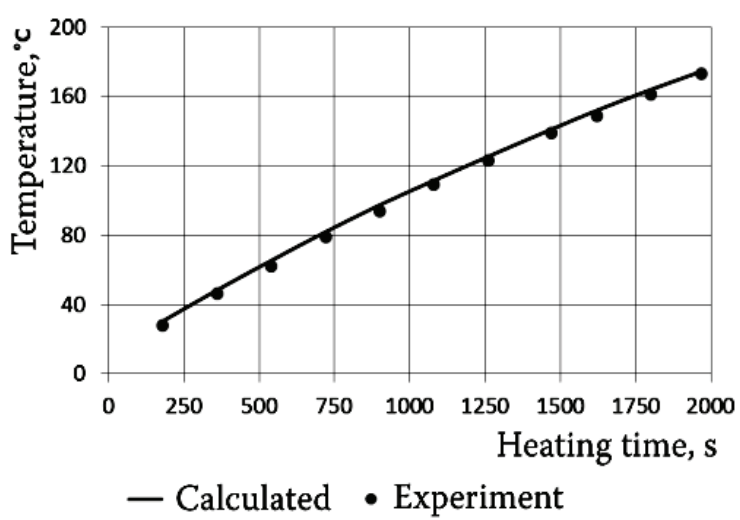

$a$-induction heating plate

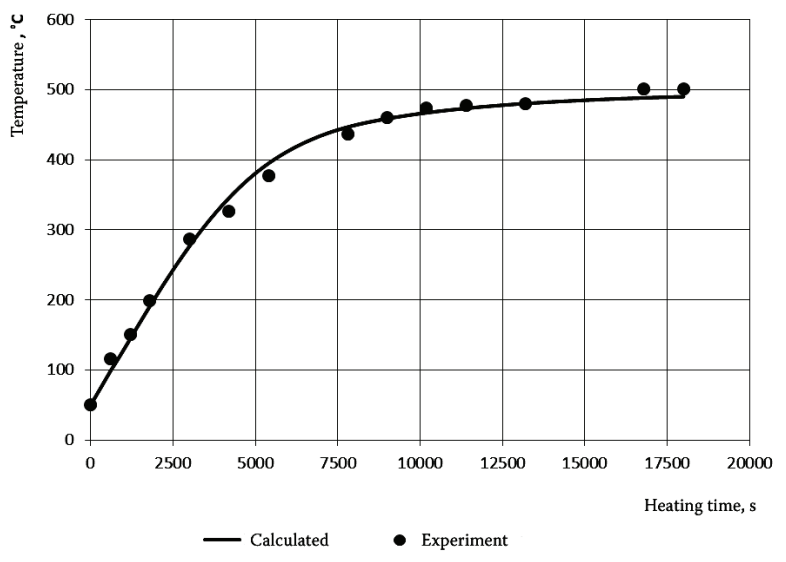

$b$ - resistive heating plate

Fig. 3. Comparing the results of the solution of equation (10) with the experimental data

Fig. 3a shows the calculations and measurements of the temperature field at the location of the control thermocouple of the plate sized $500 \times 410 \mathrm{~mm}$ with four rectangular inductors during its heating. The average absolute deviation of calculation results from the experimental data was $2.6^{\circ} \mathrm{C}$; the relative deviation was $0.7 \%$. For more details about the conditions and the results of this experiment, see [8]. Fig. $3 b$ shows a comparison of the calculation results and measurements of the temperature in the center of the working surface of the resistive heating plate sized $800 \times 800 \mathrm{~mm}$ and maintaining an operating temperature of $550^{\circ} \mathrm{C}$. The average deviation of the calculated values and the experimental data was $8.9^{\circ} \mathrm{C}$ or $1.5 \%$.

To solve the problem of minimizing the criterion (1) under the conditions (2), (3), (6), (8) (induction heating), conditions (2) - (5) (7) (8) (resistive heating) and conditions (2), (3) (8) (9) (steam heating) an algorithm based on the use of methods of computing experiment planning was developed [9]. The application of this algorithm to two industrial induction heating plates (rectangular heaters shown in Fig. 4a and concentric heaters) made it possible to optimize dimensions, arrangement and values of the heaters power, see in [9] and to find the power of resistive spiral heaters and configuration of the slots to accommodate them in the heating plate, maintaining an operating temperature of $550{ }^{\circ} \mathrm{C}$ (Fig. 4b).

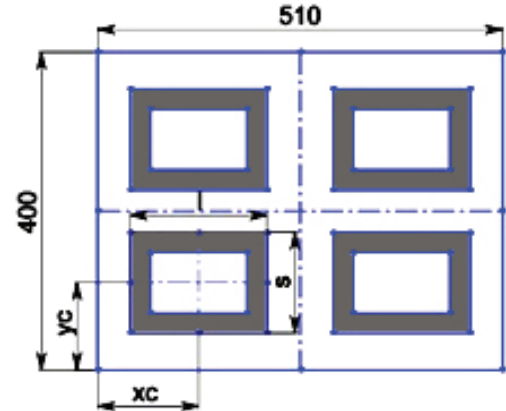

$a$-induction heating plate

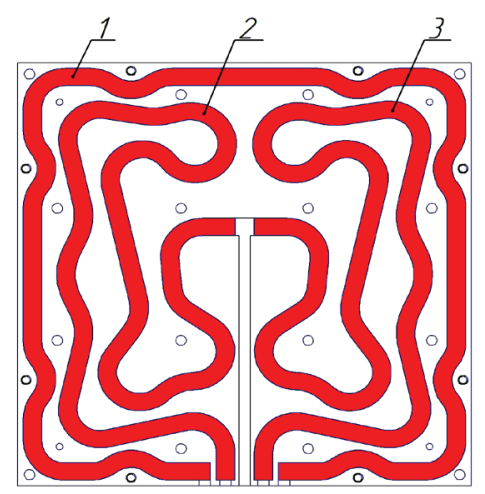

$b$ - resistive heating plate

Fig. 4. Heating plates, for which the optimization problem has been solved

\section{Results and Discussion}

Thus, the statement of the optimization problem of design parameters for the heating plates of hydraulic presses involves the search for the minimum of the criterion (1) under conditions:

- for induction heating plates - (2), (3), (6), (8);

- for resistive heating plates - (2)-(5) (7), (8)

- for steam heating plates - (2), (3), (8), (9).

The solution of equation (10) of heat distribution in the volume of the plate with internal heat sources under conditions (10), (11) and conditions (13), (14) and (15) or (16) was performed using a system of finite-element analysis ANSYS. The adequacy of the mathematical description of heat distribution in the plate volume was confirmed by the results of industrial experiments.

The problem of design optimization of heating plates as solved using the method of computational experiment planning. This method was successfully used to optimize industrial designs of induction heating and resistive heating plates.

This work was financially supported by Ministry of Education and Science of the Russian Federation within the basic part (project 8.7082.2017/8.9).

\section{References}

1. S.V. Karpushkin, S.V. Karpov, A.O. Glebov. Chem. Petr. Eng., 51(5), 388-395 (2015) 
2. I.A. Fel'dman, M.B. Gutman, G.K. Rubin, N.I. Shadrich, Raschet $i$ konstruirovanie nagrevatelej jelektropechej soprotivlenija [Calculation and design of electric resistance heaters] (M.-L.: Jenergija, 1966) (in Russian)

3. E.N. Malyigin, S.V. Karpushkin, A.O. Glebov, S.V. Karpov, Rus. Eng. Res., 36(9), 708-712 (2016)

4. P.G. Romankov, V.F. Frolov, O.M. Flisjuk, M.I. Kurochkina, Metody rascheta processov $i$ apparatov himicheskoj tehnologii [Methods for calculating the processes and devices of chemical technology] (SPb.: Himija, 1998) (in Russian)

5. N.S. Koshljakov, Je.B. Gliner, M.M. Smirnov, Uravnenija v chastnyh proizvodnyh matematicheskoj fiziki [Partial differential equations of mathematical physics] (M.: Vysshaja shkola, 1970) (in Russian)

6. A.O. Glebov, S.V. Karpov, S.V. Karpushkin, Autom. Remote Control, 75(6), 1120-1129 (2014)

7. K.A. Basov, ANSYS: Spravochnik pol'zovatelja [ANSYS: User Manual]. (M.: DMK Press, 2005) (in Russian)

8. S.V. Karpushkin, S.V. Karpov, A.O. Glebov, Transactions Tambov STU, 17(1), 110-120 (2011)

9. A.V. Ostroukh, A.O. Glebov, S.V. Karpov, S.V. Karpushkin, M.N. Krasnyanskiy, Am. J. Appl. Sci., 11(6), 939-946 (2014) 